\title{
Burden of Obstetric Fistula on the Rohingya Community in Cox's Bazar, Bangladesh
}

\author{
Iftikher Mahmood ${ }^{1}$, Nrinmoy Biswas ${ }^{1}$, Fahmida Akter ${ }^{1}$, Johanna Hansing ${ }^{1}$, Arman Mahmood ${ }^{1}$, Ashley \\ Pugh $^{1}$, Jessica Love ${ }^{1}$, Steven Arrowsmith ${ }^{2}$
}

${ }^{1}$ HOPE Foundation and Hospital, Cox's Bazar, Bangladesh

${ }^{2}$ Fistula Foundation, USA.

DOI: http://dx.doi.org/10.3126/njog.v13i2.21715

\begin{abstract}
Since August 2017, a massive influx of over 800,000 Rohingya refugees have arrived in Cox's Bazar, Bangladesh. The Rohingya state is one the poorest states in Myanmar, with ghetto-like camps and a lack of basic services and opportunities. In 1982, a new citizenship law was passed, effectively rendering the Rohingya stateless. As a result of this law, their rights to access health services have been restricted.

Now, many Rohingya are living in Cox's Bazar in tent-based refugee camps under extremely poor conditions without access to proper medical care, hygiene, sanitation, food or education. Lack of proper maternal health care, together with early marriage, malnutrition, poverty and the physical characteristics of the women in this community (small body shapes), exposes Rohingya women to a very dangerous position with high chances of developing obstetric fistula during childbirth.
\end{abstract}

HOPE Hospital provides clinical care for women affected with obstetric fistula and is the only provider and referral center of fistula care in the region. Since the influx began, many fistula repairs have been carried out on Rohingya women at HOPE Hospital. This paper looks at fistula care and the psychosocial impact of fistula on victims in the refugee population, amid a massive humanitarian crisis

Keywords: obstetric fistula, psychosocial impact of fistula, Rohingya maternal health.

\section{INTRODUCTION}

Obstetric fistula devastates the lives of more than two million women globally, according to UNFPA. The injury is a symptom of poverty, affecting women who are typically unable to access or afford medical care. In Bangladesh, where 9 in 10 women give birth at home without any trained medical help present, obstetric fistula is prevalent. The HOPE Foundation for Women and Children of Bangladesh has been at the forefront of this issue since 2011, growing community outreach programs to identify patients and training surgeons to provide high-quality care. In the final months of 2017, when the influx of Forcibly Displaced Myanmar Nationals, the Rohingya refugees began arriving in Bangladesh, we noticed a significant number of cases of obstetric fistula within this population of Rohingya refugees. This prompted us to look in-depth at the maternal health crisis facing this region as the refugee community continues to grow at a rapid pace, and to look at the ways in which we and other organizations might be able to expand our ability to provide medical care to the Rohingya community for this devastating childbirth injury.

\section{CORRESPONDENCE}

Dr. Iftikher Mahmood

HOPE Foundation and Hospital, Cox's Bazar, Bangladesh

Email: iumahmood@gmail.com

Phone: +13053180142
Obstetric fistula is predominantly caused by obstetric causes but can also occur due to provider error or trauma. In addition to physical trauma, this also results in psychosocial trauma for the woman as she is often times ostracized from her community. Those who develop obstetric fistula are often the most vulnerable. Moreover, "prolonged, obstructed labor occurs most frequently in countries where early marriage, early or frequent childbearing (before the pelvis is fully developed or after multiple births), malnutrition, small stature, general poor health and poverty are commonplace, where access to antenatal and emergency obstetrical care are limited and the use of contraception is culturally restricted or unavailable". ${ }^{1}$ Worldwide, there are at least 2 million young women living with untreated obstetric fistula in Asia and sub-Saharan Africa. ${ }^{2}$ This article seeks to understand the particulars of obstetric fistula within a defined population: the Rohingya community.

The Rohingya are a small ethnic group, of whom the majority are Muslim, who have mostly been living in the state of Myanmar. ${ }^{3}$ The Rohingya are said to be the most persecuted minority group in the world. The Rohingya have been denied citizenship since 1982 and therefore are considered 'stateless' people, mostly living in ghetto-like camps in the state of Rakhine where they are not allowed to leave without the government's permission. Their living 
conditions lack the most basic elements, and they suffer from poor health conditions. In October 2016, a government crackdown on Rohingya community was spurred by the killings of border guards, leading to widespread violence. Escaping this hostility, over 800,000 Rohingya fled to Bangladesh since August 2017 and remain in refugee camps. ${ }^{4}$ Due to the situation of the Rohingya, it has been very difficult to understand the true health conditions faced in Myanmar. The crisis has enlightened the health care community in Bangladesh as to how primitive conditions for health were and remain for those who have stayed behind, and shed light on the dire need of Rohingya women living in Bangladesh today. This paper seeks to provide an in-depth view of the health status of Rohingya, especially in relation to obstetric fistula.

\section{MATERNAL AND REPRODUCTIVE HEALTH}

This paper's sole focus is on the maternal and reproductive health of the Rohingya. Although the available data on the maternal health status of the Rohingya is limited, there are several studies that have examined this area in-depth. For example, Mahmood et $\mathrm{al}^{5}$ found that one out of seven women living in Northern Rakhine state underwent at least one unskilled abortion under unhygienic conditions. Bhatia et $\mathrm{al}^{6}$ discovered that out of the " $18.9 \%$ Rohingya households (living in refugee camps in Bangladesh) that reported a pregnancy in the prior year, the majority of pregnant women $(56.6 \%)$ received no antenatal care. Of those women who gave birth in the previous 12 months, $73.7 \%$ did so at home without a certified birth attendant". Malnutrition plagues the camps, as Guzek et al's s study revealed that the severe acute malnutrition rates are 'alarming'. The World Health Organization reported that in Rakhine state, the rate of exclusive breastfeeding is $1.3 \%$, which is the lowest in Myanmar. ${ }^{8}$ This compounds the issue of malnutrition in Rohingya children which increases the risk of obstetric compilations for young women once they become pregnant. The World Health Organization also reported that Rohingya refugees face obstacles in accessing maternal, sexual and reproductive health services in Rohingya camps; $28 \%$ of refugees reported not having access to ANC, in $36 \%$ of locations surveyed, $36 \%$ of locations reported women do not give birth in health facilities, with an estimated $14 \%$ of deliveries taking place in facilities. ${ }^{9}$ The transporting of patients for facility-based births, particularly at night, remains a challenge.

It is evident that the health of the Rohingya greatly suffered while in Myanmar but also continues to suffer in Bangladesh, both due to a lack of resources but also due to the trauma and violence experienced just prior to and during their flee from Myanmar. In Nordby's ${ }^{10}$ thesis, gender-based violence and sexual violence is specifically described, detailing the sexual violence incurred in Myanmar and within the camps in Cox's Bazar, Bangladesh. Several organizations have rushed to provide aid to the Rohingya, deploying mobile health clinics and building makeshift hospitals. HOPE Foundation for Women and Children of Bangladesh, a not for profit, 501 (C)(3) organization based in the US, is one of those organizations. HOPE has worked in Cox's Bazar since 1999 and built strong relationships with the rural community through a grassroots approach. Since 1999 over a million people have been served.

\section{FISTULA SERVICES PRIOR TO THE ROHINGYA CRISIS}

HOPE is the most experienced and highest profile provider of fistula treatment in southern Bangladesh. The organization's fistula work began in 2011 with partner, Fistula Foundation, and has since performed over 400 fistula repair surgeries. FIGO-trained fistula surgeons, Dr. Nrinmoy Biswas and Dr. Fahmida Akter, are HOPE's OB/GYN surgeons. In addition to the advanced training of these surgeons, HOPE Foundation keeps a strict monitoring and evaluation approach to surgical care. Fistula patients receive a comprehensive care program, with a full team dedicated to helping the woman regain her life postsurgery. As part of our outreach initiative, we have trained a number of village health workers, who have been essential in finding and recruiting pregnant women as well as fistula patients. HOPE Hospital is today the referral center for all the fistula cases diagnosed in Cox's Bazar, providing free treatment to all the patients. HOPE has also partnered with BRAC University and DFID to launch a Community Midwifery Diploma Program, where we are now training midwifery students through an intensive three-year course, with the goal of hiring these new midwives upon graduation. In the next few years, HOPE will have trained 250 midwives who will be 
deployed to remote villages that will help achieve the goal of preventing fistula, finding patients and perform safe deliveries. New projects and partnerships with organizations like Direct Relief and UNFPA Bangladesh are greatly expanding HOPE's fistula program by providing a full dedicated team to fistula, as well as outreach campaigns and a financial entrepreneurship project for fistula sufferers.

\section{CHALLENGES PRESENTED BY THE ROHINGYA CRISIS}

As they have served the Rohingya people, the doctors of HOPE Foundation have noted that obstetric fistula is one of the most measurable sufferings of Rohingya women due to health care neglect in Myanmar. The Rohingya patients we have served report that there is no government health facility for which they have access. There are health facilities within the Rakhine community, but the Rohingya are not permitted to enter. There are some private hospitals, but the Rohingya are not able to afford private care. Due to poor access to health care, Rohingya women suffer from malnutrition. This enables an unsafe condition for pregnancy, as women/girls who are malnourished do not physically develop fully, and most notably, possess narrow birth canals. ${ }^{10}$ Narrow birth canals pose a significant risk for obstructed labor during delivery, and given the Rohingyas' lack of health care access, women routinely deliver at home without a skilled birth attendant present. If a fistula develops, it remains untreated. As there is no fistula repair surgery available to them in Myanmar, the Rohingya women suffer - some, for a great many years.

Many of the challenges we have faced in treating fistula among the Rohingya population over the past fifteen months are similar to challenges we faced on a daily basis when we were focused solely on the vulnerable population in the Cox's Bazar region. Women with fistula often do not know that they suffer from a treatable injury. They tend to hide their condition, for fear of ostracization from the society on which they must depend. This is especially compounded in a refugee crisis situation. Further, we have seen many Rohingya women who became pregnant as a result of rape from the Myanmar army during the campaign of violence and destruction that prompted these women to flee to Bangladesh. This has resulted in taboo pregnancies, for which a woman will not seek antenatal care and which she may find means of terminating, in an unsafe manner. This cultural stigma adds to a woman's hesitation to come forward for fistula treatment, especially if her fistula is the devastating end result of an unwanted pregnancy. In the refugee camp environment, there are also a number of challenges that have prevented women who do want fistula care from accessing it. Monsoon rains last for several months during the calendar year, and related flooding makes roads impassable by foot or by vehicle. The growing population is also a challenge. While hundreds of aid organizations have arrived to help provide care to the refugee community, there are not enough medical providers to care for every person who needs help; not every provider operating temporary mobile clinics throughout the camps has the training necessary to identify obstetric fistula if they come upon it.

Coordination amongst the government and aid organizations in a refugee crisis is also challenging. While the help is desperately needed, overarching coordination between the government and aid groups arriving from countries around the world - each with their own language, customs, and perspective on this crisis - is also a challenge. HOPE Foundation is the only hospital able to provide free fistula care at our flagship HOPE Hospital. Organizations who identify Rohingya women suffering from fistula refer patients to us, which has prompted a backlog in our ability to provide care to every woman who needs it. Indeed, over the past year, the fistula patients receiving care at HOPE Hospital have spent a combined 1,530 days in the hospital, or 15 nights, on average. As a 40-bed hospital with a 15-bed fistula ward, we simply do not have the space to accommodate every woman who needs surgery.

\section{LESSONS LEARNED}

Currently, HOPE Foundation provides the majority of fistula repair surgery in the greater Chittagong Division of Bangladesh. From October 2017 to September 2018, 101 fistula patients have been scheduled for obstetric fistula repair surgery. Fortunately, we have found that during this time frame, the majority of the patients we have treated (46 percent) have been able to receive fistula treatment within less than one year of developing a fistula. We are confident that the combined efforts of HOPE and our partners working in the camps over the last year have worked, as women who have been living in the camps are more open to 
seeking and accepting help for their fistula soon after it develops. Of the women treated since the start of the influx, 80 percent are under the age of 40 . This leads us to believe that younger patients are more willing to seek and accept care. But the fact that our second largest patient cohort, women living with fistula more than 10 years ( 24 percent), is nearly half that of our largest cohort, mentioned above, leads us to believe that older patients, who have suffered longer, are less likely to seek help for their injury. Indeed, patients over age 50 made up only 9 percent of the population we have treated.

We learned a great deal about the impact of fistula on Rohingya women's lives, and how to provide not only reparative surgery, but also about the need to provide psychosocial care. Women we treated were unable to access or were denied access to antenatal care services in Myanmar. Complications at birth sometimes resulted in admission to health facilities in the Rakhine district, but, if a woman's delivery resulted in obstetric fistula, there was no place for her to go to get help. Too often, this resulted in the woman being abandoned by her husband and forced to live with her injury. Women whose husbands did not abandon them often lost their husbands in violence, at the hands of the Myanmar military. Many women, including women suffering from fistula, suffered rape, torture and other extreme forms of violence that caused severe psychological damage. We have always known that counseling should be provided to all patients post-treatment, but as we heal more and more Rohingya women who have suffered so greatly, physically and mentally, HOPE has made psychosocial care an important part of our fistula repair process.

\section{FUTURE STRATEGIES}

Rohingya women urgently need fistula screening and treatment: Women living in the camps have suffered dearly. Many have lost their husbands and other loved ones, having been a witness and too often subjected to brutal violence before fleeing to Bangladesh. Now living in refugee camps that are five times the United Nations' recommended standard for refugee camps, women who may previously have been able to hide their condition can no longer do so. They are living in extreme conditions, with no place to hide. Many suffer verbal and physical abuse because of their smell, making an already unbearable condition in an unbearable situation even worse. Furthermore, in the camps, one must be part of a community of people to be able to survive the harsh conditions in the camp. For women suffering from fistula, this can be very difficult. Shunned because of their smell, they too often lack access to food, water, and shelter. Yet their condition is treatable. But only if women step forward to seek help.

Psychosocial care is equally as important as reparative surgery: As we have already seen in our completed case log, Rohingya women have suffered for years first, in Myanmar, they were denied access to health services that could have ensured a safe delivery or an emergency

C-section that would have prevented their condition. Second, the brutal displacement campaign traumatized Rohingya community in unspeakable ways. And finally, at the hands of their own community, which has too often ostracized fistula patients, unable to bear their smell. These women have suffered so much, for so long. Their strength and resilience have been remarkable, but no one can bear this burden for so long without suffering mentally and emotionally. It is critical that these traumatized women have convenient, regular access to psychosocial care in addition to receipt of clinical care - to heal their minds, along with their bodies.

Care providers must complete specialized training before working with this extremely sensitive, vulnerable community: The extent to which Rohingya women suffering from fistula have endured physical violence and mental abuse should not be overlooked. These women are in an extremely fragile state and must be attended to carefully. In addition to the trauma witnessed and the ever-present physical condition from which they are suffering, Rohingya women in the camps have limited educational opportunities, virtually no chance of working and-as a stateless people - an uncertain long-term future. Between the trauma and the hopelessness, the mental health needs are extraordinary. Yet, there is a huge gap between the mental health needs of this vulnerable population and the support available. Investments must be made within human capacity to provide aid in a manner appropriate to the experiences endured by these women.. To help these women overcome the horrors they have lived, specialized training must be provided to the clinicians and mental health professionals coming to their aid in this devastating and unique humanitarian emergency. 


\section{CONCLUSION}

It is estimated that there may be over 2,000 obstetric fistula victims in the Rohingya refugee community in Cox's Bazar, Bangladesh. The international community of fistula care providers should expand their services to help the fistula sufferers in this community.

\section{REFERENCES}

1. The Bill and Melinda Gates Institute for Population and Reproductive Health. Prevention and Treatment of Obstetric Fistula: Identifying Research Needs and Public Health Priorities, Meeting Summary; 2005.

2. World Health Organization. 10 facts on obstetric fistula Geneva: WHO; 2018. Available at https://www.who.int features/factfiles/obstetric_fistula/en/

3. Aljazeera. Who are the Rohingya? Available at https:// www.aljazeera.com/indepth/features/2017/08/rohingyamuslims-170831065142812.html

4. International Organization for Migration. IOM Bangladesh: Rohingya Humanitarian Crisis Response - External Update (1 - 7 June 2018); 2018. Available at https://reliefweb.int/report/ bangladesh/iom-bangladesh-rohingya-humanitarian-crisisresponse-external-update-1-7-june-2018

5. Mahmood SS, Wroe E, Fuller A, Leaning J. The Rohingya People of Myanmar: health, human rights and identity. Lancet. 2017;389:1841-50.
6. Balsari S, Bhatia A, Fuller A, Leaman B, Mahmud A, Morshed KAM, et al. Rapid Needs Assessment in Cox's Bazar Phase 1: March 2018. Boston, USA: FXB Center for Health and Human Rights; 2018.

7. Guzek J, Siddiqui R, White K, Van Leeuwen C, Onus R. Medicins Sans Frontiers: Health Survey in Kutupalong and Balukhali Refugee Settlements, Cox's Bazar, Bangladesh: Survey Report; 2017.

8. World Health Organization. Bangladesh: Rohingya Refugee Crisis 2017-2018 - Public Health Situation Analysis; 2018.

9. World Health Organization. Mortality and Morbidity Weekly Bulletin (MMWB): Cox's Bazar, Bangladesh, Volume No 6: 19 November 2017; 2017a http://wwwsearo.who.int/ bangladesh/mmwbvol6.pdf

10. Nordby L. Gender-based violence in the refugee camps in Cox Bazar -A case study of Rohingya women's and girls' exposure to gender-based violence. Thesis submitted to Uppsala University; 2018 